\title{
Seasonal polyphenism in body size and juvenile development of the swallowtail butterfly Papilio xuthus (Lepidoptera: Papilionidae)
}

\author{
SHINYA KOMATA and TEIJ SOTA
}

Department of Zoology, Graduate School of Science, Kyoto University, Kitashirakawa-oiwakecho, Sakyo, Kyoto 606-8502, Japan; e-mails: komata@terra.zool.kyoto-u.ac.jp, sota@terra.zool.kyoto-u.ac.jp

Key words. Lepidoptera, Papilionidae, Papilio xuthus, seasonal polyphenism, body size variation, adaptive growth decision, protandry, temperature-size rule, time constraint

\begin{abstract}
Seasonal polyphenism in adults may be a season-specific adaptation of the adult stage and/or a by-product of adaptive plasticity of the juvenile stages. The swallowtail butterfly Papilio xuthus L. exhibits seasonal polyphenism controlled by photoperiod. Adults emerging in spring from pupae that spend winter in diapause have smaller bodies than adults emerging in summer from pupae that do not undergo diapause. Pupal diapause is induced by short-day conditions typical of autumn. To explore the interactive effects of temperature and developmental pathways on the variation in adult body size in $P$. xuthus, we reared larvae at two temperatures $\left(20^{\circ} \mathrm{C}, 25^{\circ} \mathrm{C}\right)$ under two photoperiods $(12 \mathrm{~L}: 12 \mathrm{D}$ and $16 \mathrm{~L}: 8 \mathrm{D})$. Pupal weight and adult forewing length were greater in the generation that did not undergo diapause and were greater at $25^{\circ} \mathrm{C}$ than at $20^{\circ} \mathrm{C}$. Thus, body size differences were greatest between the individuals that were reared at the longer day length and higher temperature and did not undergo diapause and those that were reared at the shorter day length and lower temperature and did undergo diapause. Unlike in other Lepidoptera, larvae of individuals that undergo diapause had shorter developmental times and higher growth rates than those that did not undergo diapause. This developmental plasticity may enable this butterfly to cope with the unpredictable length of the growing season prior to the onset of winter. Our results indicate that there are unexplored variations in the life history strategy of multivoltine Lepidoptera.
\end{abstract}

\section{INTRODUCTION}

Temperate insects must cope with environmental seasonality. A notable feature of seasonal adaptation in multivoltine species is seasonal polyphenism, defined as seasonal phenotypic variations among generations attributable to phenotypic plasticity (Shapiro, 1976; Lively, 1986; Moran, 1992). In many butterflies, such polyphenism involves seasonal variation in adult phenotypes, including wing pattern, body size (wing length), and behaviour. These differences may be attributable to the adaptation of adults and/or may be by-products of adaptation and constraints in juvenile stages (Gotthard \& Nylin, 1995; Brakefield \& Frankino, 2009; Friberg \& Karlsson, 2010). It is necessary to study adult seasonal polyphenism from the viewpoint of adaptation and constraints at the juvenile stage because variations in some adult traits may reflect those in juvenile development and growth patterns. In particular, variation in adult body size may be caused by differences in juvenile development and growth, and may be related to adaptive "growth decisions" (Gotthard, 2008) made when seasonal conditions are variable.

Herein, we address the relationship between juvenile developmental patterns and seasonal polyphenism in adult body size. Different seasonal forms usually follow alterna- tive developmental pathways, in which juveniles develop either directly or in a delayed manner in which the intervening period is spent in diapause. Divergence of the developmental pathway should be selectively controlled by seasonally variable environmental conditions. Adaptive juvenile growth patterns or growth decisions should depend on alternative developmental pathways because selection pressures differ according to the seasonal conditions specific to each developmental pathway (Wiklund et al., 1991; Friberg et al., 2011, 2012; Aalberg Haugen et al., 2012; Kivelä et al., 2012, 2013; Välimäki et al., 2013a, b, 2015).

One important seasonal factor associated with alternative developmental pathways is the time available for growth and reproduction (Kivelä et al., 2013), which may profoundly affect both growth decisions and ultimate body size (Gotthard, 2008). Among butterflies, a general pattern emerges in which individuals that directly develop into adults exhibit shorter developmental times and higher growth rates in the larval stage than those that enter diapause (Wiklund et al., 1991; Wiklund \& Friberg, 2011; Aalberg Haugen et al., 2012; Friberg et al., 2012; Kivela et al., 2012). These developmental traits may have been selected for because they improve the intrinsic rate of increase (individual fitness) in periods when the time for growth and 
reproduction is restricted. Conversely, if overwintering is possible only when pupae enter diapause, all larvae must complete their development before the onset of winter, and the limited time available for larval development can select for a shorter development time and a higher growth rate in diapause generations. In such cases, the final body size of the diapause generation may be smaller if the increased growth rate cannot compensate for the reduction in final body size due to the shorter larval period. However, body size is influenced by several factors, including temperature, and the relationship between body size and alternative developmental pathways can be variable (Kivelä et al., 2013). Some insects follow the "temperature-size rule", in which individuals that develop at high temperatures have smaller bodies (Atkinson, 1994). However, the opposite pattern has been described in other insects (Atkinson, 1994, 1995, 1996; Cabanita \& Atkinson, 2006; Kingsolver et al., 2007). In species with short generation times and multiple generations, temperature rather than time constrains growth and development, and the ultimate body size is determined by the thermal reaction norm (Chown \& Gaston, 1999).

The Papilio species (Lepidoptera: Papilionidae) in temperate Japan are multivoltine insects, the pupae of which overwinter in diapause; some species exhibit seasonal polyphenism in wing pattern and body size. Such body size polyphenism shares a common pattern among species. The spring forms are smaller than the summer forms (Fukuda et al., 1982). Papilio xuthus is a species exhibiting seasonal polyphenism; spring adults emerging from overwintering (diapause) pupae have brighter wing colours and are smaller in terms of wing size than are summer adults emerging from pupae that do not undergo diapause (Tanaka \& Tsubaki, 1984; Watanabe \& Nozato, 1986; Fig. 1). Different developmental pathways can be induced by manipulating the day length during larval development. Pupal diapause is induced by short-day conditions during the larval period (Ichinose, 1974; Tanaka \& Tsubaki, 1984). The determinant of adult body size in $P$. xuthus was studied by Tanaka \& Tsubaki (1984), who focused on differences in rates of food consumption under short- and long-day conditions at a constant temperature. They found that larvae consume less food, resulting in lighter pupae and shorter adult forewing length under short-day conditions than under longday conditions. Their study, however, did not determine sexual differences and did not test for effects of temperature, although these factors can affect larval growth and development patterns.

The objective of this study was to clarify whether there is a difference in development times and growth rates between generations that undergo and do not undergo diapause, and whether temperature during larval development affects the variation in adult body size in P. xuthus. Because the larvae of spring adults develop during a cooler season (September-October) than that experienced by the larvae of summer adults, the body size of the spring adults may be smaller if the converse of the temperature-size rule applies. The temperature-size rule is predicted to hold true only at temperatures beyond the population optimum (Davidow- itz \& Nijhout, 2004). Thus, because autumn temperatures before overwintering are typically lower than summer temperatures, the observed difference in the sizes of the spring and summer adults are not predicted by the normal temperature-size rule. To explore the influence of temperature and sex on variation in adult body size we reared $P$. xuthus at two constant temperatures $\left(20^{\circ} \mathrm{C}\right.$ and $\left.25^{\circ} \mathrm{C}\right)$ under two different photoperiods: $12 \mathrm{~L}: 12 \mathrm{D}$ and $16 \mathrm{~L}: 8 \mathrm{D}$.

\section{MATERIAL AND METHODS}

\section{Study species and experiments}

Papilio xuthus ranges widely in the temperate zones in China and Japan, and its larvae feed on several species of Rutaceae (Fukuda et al., 1982). On the main islands of Japan, P. xuthus emerges as an adult from May to October, overwinters in the pupal stage and has three-to-five generations per year (Fukuda et al., 1982). We used P. xuthus captured in Kyoto City, Japan $\left(35^{\circ} 03^{\prime} \mathrm{N}, 135^{\circ} 78^{\prime} \mathrm{E}\right)$. We captured two summer females (A and B) on 28 August 2012. These females laid eggs in the laboratory and the larvae that hatched from these eggs were reared at $25^{\circ} \mathrm{C}$ under a $16 \mathrm{~L}: 8 \mathrm{D}$ photoperiod to obtain summer adults. We chose three males and three females and used hand pairing to mate two pairs using females from $A$ and males from $B$, and one pair with a female from B and a male from A. The females were individually reared in cages containing citrus leaves; approximately 300 eggs were obtained in total. To study the characteristics of larval development, these eggs were immediately divided into four groups and reared under different conditions: (1) $16 \mathrm{~L}: 8 \mathrm{D} / 20^{\circ} \mathrm{C}$, (2) $12 \mathrm{~L}: 12 \mathrm{D} / 20^{\circ} \mathrm{C}$, (3) $16 \mathrm{~L}: 8 \mathrm{D} / 25^{\circ} \mathrm{C}$ and (4) $12 \mathrm{~L}: 12 \mathrm{D} / 25^{\circ} \mathrm{C}$. When the larvae hatched, they were weighed on an electronic balance (sensitivity: $0.0001 \mathrm{~g}$ ) and individually reared in small Petri dishes (diameter, $40 \mathrm{~mm}$; height $12 \mathrm{~mm}$ ). The larvae were fed an artificial diet (Insecta F-II; Nosan, Kanagawa, Japan) and dried leaves of Zanthoxylum ailanthoides collected from the field. The Insecta F-II:dried leaf weight ratios were $1: 1$ until 3 days after hatching, $3: 1$ until the fourth-instar and then $7: 1$ until they completed their development. Last-instar larvae (5th instar) were kept individually in plastic cups (diameter, $130 \mathrm{~mm}$; height, $100 \mathrm{~mm}$ ). After pupation, body weights were measured using the electronic balance described above. The development time was defined as the number of days from hatching to pupation. The growth rate was calculated as: [ln (pupal weight) - $\ln$ (hatching weight)]/ larval time (Gotthard et al., 1994). If individuals did not emerge within 30 days of pupation, they were assumed to be in diapause (Ichinose, 1974) and stored at $4^{\circ} \mathrm{C}$ in the dark. After 60 days they were returned to the initial growth regimes. The pupal development time was the number of days from pupation to adult emergence for non-diapause individuals. For individuals that undergo diapause, however, we recorded the post-diapause pupal development time (i.e., the number of days between the end of chilling and adult emergence). When adults emerged, their forewing lengths were measured using digital electronic calipers (sensitivity: $0.01 \mathrm{~mm}$ ).

\section{Statistical analysis}

We explored the effects of temperature, developmental pathway and sex on larval development time, pupal weight, growth rate, pupal development time and adult forewing length using linear mixed-effects models. Temperature, developmental pathway, sex and their interactions were fixed factors, and the parents were included as a random factor. The pupal development times of diapause and non-diapause generations were analyzed separately. The sample sizes for our analyses were 131 and 136 individuals for the diapause and non-diapause generations, respectively. In all 


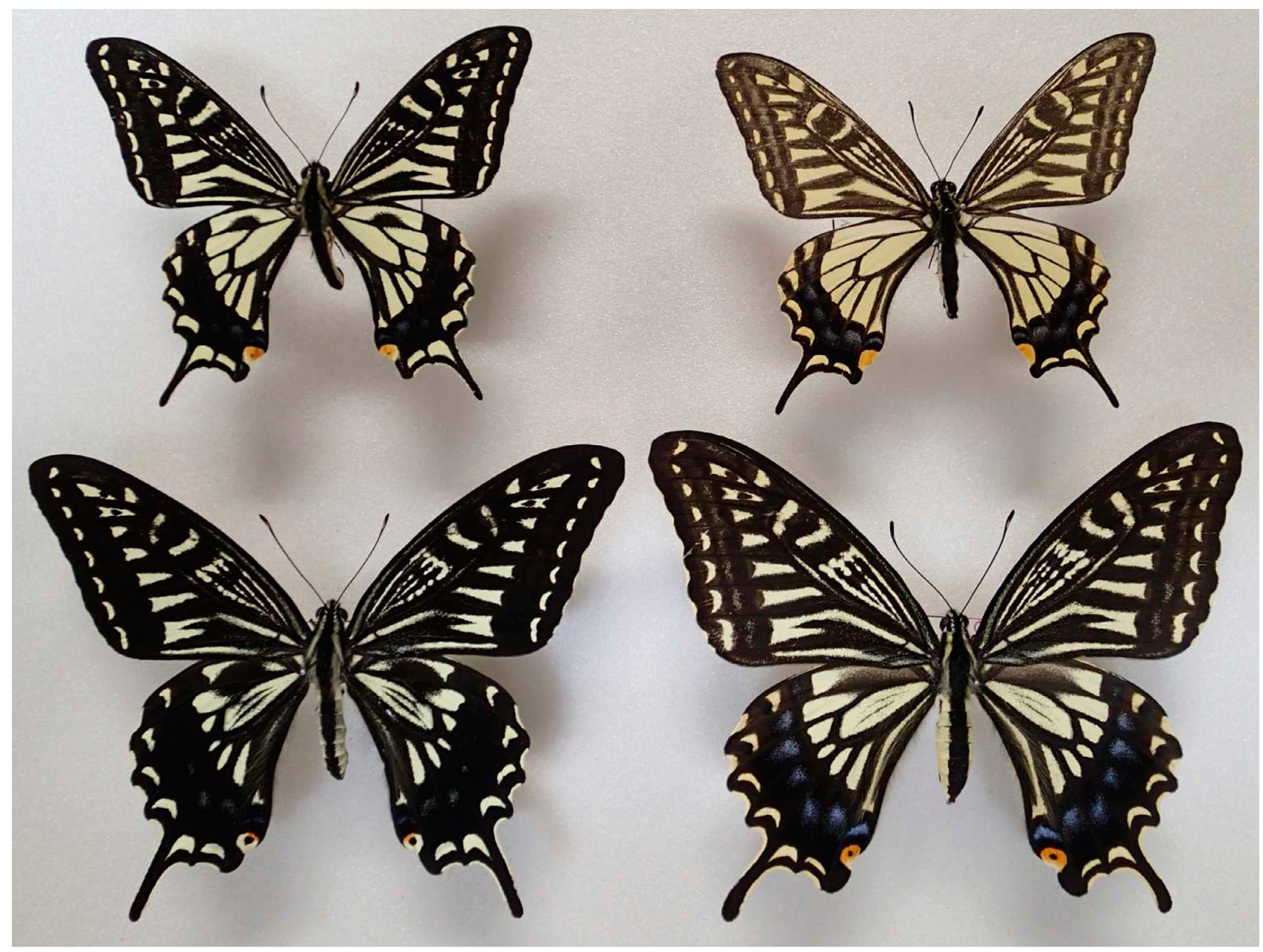

Fig. 1. Seasonal differences in the form of the adults of Papilio xuthus: Spring male (top left), spring female (top right), summer male (bottom left) and summer female (bottom right). All individuals were collected in Kyoto City, Japan, in 2012.

analyses, a model-averaging approach based on Akaike information criterion (AIC) scores was performed to identify the relative importance of the variables and generate weighted coefficient estimates. Candidate models that differed from the AIC of the best-fitting model by $<2$ were selected. We used the 'subset' (or 'conditional') average method, whereby only models containing the focal parameter were averaged. We used a threshold of 0.7 to decide the relative importance of individual parameters considered significant. All analyses were performed using the 'lme4' and 'MuMIn' packages in the R software version 3.2.2 (Bates et al., 2015; R Core Team, 2015; Bartoń, 2016).

\section{RESULTS}

As expected, all of the individuals entered pupal diapause when reared under short day conditions (12L: 12D) but not under long day conditions (16L:8D), at both temperatures. The phenotype of adults emerging from non-diapausing pupae was that of the summer form, whereas the phenotype of adults emerging from diapausing pupae after chilling was that of the spring form. The larval development time was shorter at $25^{\circ} \mathrm{C}$ than at $20^{\circ} \mathrm{C}$, in the diapause generation than in the non-diapause generation, and in males than in females (Fig. 2A and Table 1). The interaction between temperature and developmental pathways significantly affected the larval development time, but did not affect the above mentioned trends. The pupal weight was greater at $25^{\circ} \mathrm{C}$ than at $20^{\circ} \mathrm{C}$, in the non-diapause generation than in the diapause generation, and in females than in males (Fig. $2 \mathrm{~B}$ and Table 1). The interaction between developmental pathways and sex significantly affected pupal weight but did not affect the above mentioned trends. The growth rate was higher at $25^{\circ} \mathrm{C}$ than $20^{\circ} \mathrm{C}$ and in the diapause generation than in the non-diapause generation (Fig. $2 \mathrm{C}$ and Table 1).

The pupal development time was shorter at $20^{\circ} \mathrm{C}$ than at $25^{\circ} \mathrm{C}$ in the diapause generation. However, the pupal development time was shorter at $25^{\circ} \mathrm{C}$ than at $20^{\circ} \mathrm{C}$ in the non-diapause generation (Fig. 3A and Table 1). Male adults emerged significantly earlier than female adults (i.e., protandry) in the diapause generation, but not in the nondiapause generation (Fig. 3A and Table 1). Adult forewing length exhibited the same trend as pupal weight, and the interaction effect of temperature and developmental pathway was significant (Fig. 3B and Table 1).

\section{DISCUSSION}

Pupal weight and adult forewing length were greater when individuals were reared at the higher temperature (Figs 2B and 3B). This pattern was recorded for both dia- 

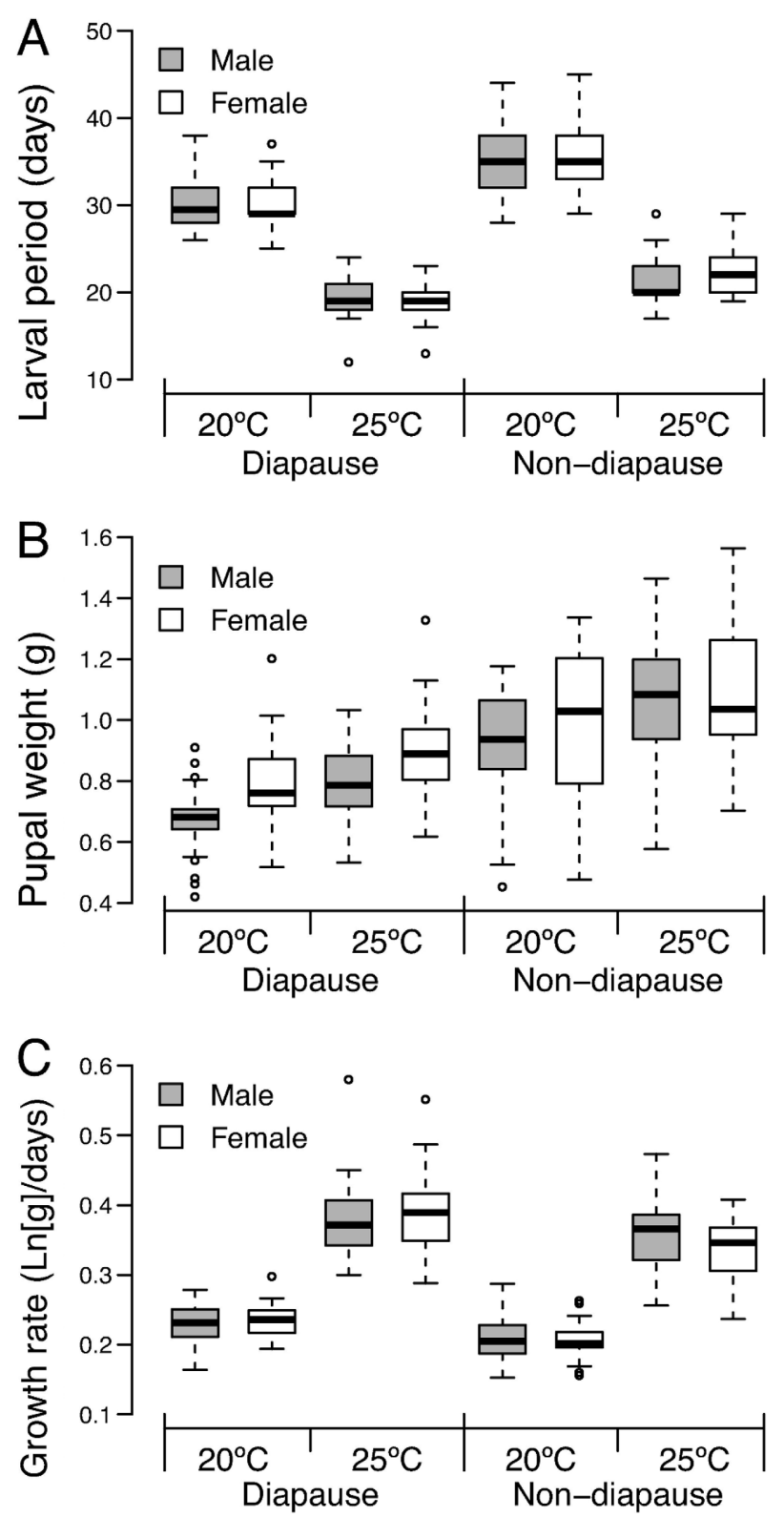

Fig. 2. The effects of developmental pathway on larval development time (A), pupal weight (B) and growth rate (C) when Papilio xuthus was reared at two constant temperatures. Grey boxes: males; white boxes: females. The bold horizontal line in each box is the median and the top and bottom of the box are one quartile above and below the median, respectively. The whiskers extend to the most extreme data points within a 1.5 interquartile range. Dots are data beyond the whiskers.

pause and non-diapause development and is the opposite of that predicted by the temperature-size rule (Atkinson, 1994), which indicates that temperature is a factor that promotes body size differences related to the seasonal polyphenism in P. xuthus. In Kyoto City (where our experimental population was collected), the average temperature from May to August (during which non-diapause generations develop) is $24.3^{\circ} \mathrm{C}$ and from September to October (the larval period of the diapause generation) is $21.0^{\circ} \mathrm{C}$ (Japan Meteorological Agency data from 1981-2010); these average temperatures correspond to our experimental temperatures. Thus, lower temperatures in autumn (short-


Fig. 3. Pupal development times (A) and adult forewing lengths (B) of Papilio xuthus that followed different developmental pathways at two constant temperatures. Grey boxes: males; white boxes: females. The bold horizontal line in each box is the median, and the top and bottom of the box are one quartile above and below the median, respectively. The whiskers extend to the most extreme data within a 1.5 interquartile range. Dots are data points beyond the whiskers.

day conditions) compared to those in summer (long-day conditions) would increase the difference in adult body size of the spring and summer forms.

We also found that larvae in the diapause generation (overwintering in pupal diapause) had a higher growth rate, shorter development time and smaller pupal and adult sizes than larvae in the non-diapause generations (Figs 2 and 3). This pattern is inconsistent with that observed in other Lepidoptera (Wiklund et al., 1991; Wiklund \& Friberg, 2011; Aalberg Haugen et al., 2012; Friberg et al., 2012; Kivela et al., 2012). Our results for P. xuthus may be explained as follows. In autumn, larvae of the diapause generation may have less time to complete their development than larvae of non-diapause generations. Therefore, larvae in the diapause generation may have been selected for a shorter larval period and higher growth rate, which allows development to be completed before the onset of winter. The onset of winter is somewhat unpredictable, and natural selection may favour a shorter larval period to avert the risk of death due to the first frost (Taylor \& Spalding, 1989). A shorter larval development time may result in the smaller body size of the spring form. Kivelä et al. (2016) also show that environmental uncertainty is the 
Table 1. Model-averaged coefficients and relative importance of the explanatory variables in the developmental characteristics and body sizes of Papilio xuthus reared under various conditions. $\mathrm{df}=1$ for all factors.

\begin{tabular}{|c|c|c|c|c|c|}
\hline $\begin{array}{l}\text { Dependent variable } \\
\text { Factor }\end{array}$ & Estimate & SE & $z$ & $P$ & $\begin{array}{c}\text { Relative } \\
\text { importance }\end{array}$ \\
\hline \multicolumn{6}{|l|}{ Larval development time } \\
\hline (Intercept) & 30.1936 & 0.52137 & 57.699 & $<0.0001$ & \\
\hline Developmental pathway [non-diapause] & 5.70725 & 0.74133 & 7.674 & $<0.0001$ & 1.00 \\
\hline Temperature $\left[25^{\circ} \mathrm{C}\right]$ & -11.12525 & 0.55013 & 20.129 & $<0.0001$ & 1.00 \\
\hline Dev. path. [non-diapause] ${ }^{*}$ Temp. $\left[25^{\circ} \mathrm{C}\right]$ & -2.4141 & 0.74077 & 3.415 & 0.00064 & 1.00 \\
\hline Sex [male] & -0.1378 & 0.60202 & 0.103 & 0.918 & 0.76 \\
\hline Dev. path. [non-diapause] * Sex [male] & -1.40557 & 0.74186 & 1.886 & 0.0593 & 0.57 \\
\hline \multirow{2}{*}{\multicolumn{6}{|c|}{ Pupal weight }} \\
\hline & & & & & \\
\hline (Intercept) & 0.79437 & 0.04753 & 16.639 & $<0.0001$ & \\
\hline Developmental pathway [non-diapause] & 0.19949 & 0.03206 & 6.201 & $<0.0001$ & 1.00 \\
\hline Sex [male] & -0.1072 & 0.03049 & 3.503 & 0.00046 & 1.00 \\
\hline Temperature $\left[25^{\circ} \mathrm{C}\right]$ & 0.12643 & 0.02281 & 5.519 & $<0.0001$ & 1.00 \\
\hline Dev. path. [non-diapause] * Sex [male] & 0.06287 & 0.03811 & 1.642 & 0.101 & 0.72 \\
\hline Dev. path. [non-diapause] * Temp. $\left[25^{\circ} \mathrm{C}\right]$ & 0.01868 & 0.03796 & 0.49 & 0.624 & 0.16 \\
\hline Sex $\left[\right.$ male] ${ }^{*}$ Temp. $\left[25^{\circ} \mathrm{C}\right]$ & 0.01847 & 0.03813 & 0.482 & 0.63 & 0.16 \\
\hline \multicolumn{6}{|l|}{ Growth rate } \\
\hline (Intercept) & 0.235565 & 0.007277 & 32.24 & $<0.0001$ & \\
\hline Developmental pathway [non-diapause] & -0.034211 & 0.009499 & 3.592 & 0.000328 & 1.00 \\
\hline Temperature $\left[25^{\circ} \mathrm{C}\right]$ & 0.146853 & 0.006598 & 22.171 & $<0.0001$ & 1.00 \\
\hline Sex [male] & -0.007638 & 0.007453 & 1.02 & 0.308 & 0.64 \\
\hline Dev. path. [non-diapause] * Sex [male] & 0.020456 & 0.009862 & 2.065 & 0.039 & 0.64 \\
\hline Dev. path. [non-diapause] ${ }^{*}$ Temp. $\left[25^{\circ} \mathrm{C}\right]$ & -0.009372 & 0.009853 & 0.947 & 0.344 & 0.32 \\
\hline Sex $\left[\right.$ male] ${ }^{*}$ Temp. $\left[25^{\circ} \mathrm{C}\right]$ & 0.005269 & 0.009864 & 0.532 & 0.595 & 0.14 \\
\hline \multicolumn{6}{|l|}{ Pupal development time: diapause generation } \\
\hline (Intercept) & 31.7549 & 1.4892 & 21.118 & $<0.0001$ & \\
\hline Sex [male] & -8.958 & 1.3843 & 6.409 & $<0.0001$ & 1.00 \\
\hline Temperature $\left[25^{\circ} \mathrm{C}\right]$ & 8.4223 & 1.4043 & 5.94 & $<0.0001$ & 1.00 \\
\hline Sex $\left[\right.$ male ${ }^{*}$ Temp. $\left[25^{\circ} \mathrm{C}\right]$ & 0.2151 & 2.4715 & 0.086 & 0.931 & 0.27 \\
\hline \multicolumn{6}{|l|}{ Pupal development time: non-diapause generation } \\
\hline (Intercept) & 20.364 & 0.2466 & 81.956 & $<0.0001$ & \\
\hline Temperature $\left[25^{\circ} \mathrm{C}\right]$ & -9.93 & 0.307 & 32.185 & $<0.0001$ & 1.00 \\
\hline Sex [male] & -0.2571 & 0.2971 & 0.86 & 0.39 & 0.57 \\
\hline Sex [male] * Temp. $\left[25^{\circ} \mathrm{C}\right]$ & 0.7242 & 0.3649 & 1.966 & 0.049 & 0.41 \\
\hline \multicolumn{6}{|l|}{ Forewing length } \\
\hline (Intercept) & 42.0803 & 0.8437 & 49.652 & $<0.0001$ & \\
\hline Developmental pathway [non-diapause] & 5.7813 & 0.6216 & 9.267 & $<0.0001$ & 1.00 \\
\hline Sex [male] & -2.7475 & 0.5059 & 5.412 & $<0.0001$ & 1.00 \\
\hline Temperature $\left[25^{\circ} \mathrm{C}\right]$ & 1.9634 & 0.473 & 4.132 & $<0.0001$ & 1.00 \\
\hline Dev. path. [non-diapause] ${ }^{*}$ Temp. $\left[25^{\circ} \mathrm{C}\right]$ & 1.4738 & 0.6289 & 2.333 & 0.020 & 1.00 \\
\hline Dev. path. [non-diapause] * Sex [male] & 1.1505 & 0.6303 & 1.817 & 0.069 & 0.73 \\
\hline Sex $[\text { male }]^{*}$ Temp. $\left[25^{\circ} \mathrm{C}\right]$ & -0.1238 & 0.6309 & 0.195 & 0.845 & 0.20 \\
\hline
\end{tabular}

determinant of differentiation between direct and diapause pathways. Our experiment did not distinguish the effect of developmental pathways from that of photoperiod. Some insects increase their growth rates under season-end photoperiods without altering their developmental pathway (Leimar, 1996; Gotthard, 1998). Further experiments are needed to test whether variation in the growth pattern under different photoperiods is related to adaptation to changing seasonal conditions or unpredictable length of the season, or both, in P. xuthus.

Unlike the results of the current study, Tanaka \& Tsubaki (1984) found no significant difference in development time between larvae reared under short-day and long-day conditions. They used a relatively small number of individuals in their experiment and hence may have failed to detect the difference in larval development times. These authors demonstrate that larvae consumed less food under shortday than long-day conditions and suggest that the limited availability of edible foliage in the fall may select for the consumption less food, resulting in smaller adult body sizes in the diapause generation. The leaf quantity and quality of the Rutaceae trees used by $P$. xuthus may decrease towards late autumn, especially those of deciduous Rutaceae trees like Japanese pepper (Zanthoxylum piperitum). However, it is questionable whether selection favours a lower rate of food consumption when food availability is limited. Teder et al. (2010) show that late-season bivoltine moth larvae grew larger than early-season larvae despite the poorer food quality during late summer.

Protandry was evident in diapause, but not non-diapause, generations (Fig. 3A). Protandry may be caused by a between-sex difference in diapause termination or a difference in body size. Typically, a trade-off exists between protandry and large male size; female monogamy selects for protandry and female polygamy for large male size (Wiklund et al., 1991). Between-generation differences in protandry may indicate that the various annual generations of $P$. xuthus have different reproductive strategies. The time needed for male sexual maturation is physiologically constrained (Larsdotter Mellström et al., 2010). Typically, most males cannot mate until the second day after emergence, although females can mate immediately after emergence. The evolution of protandry may be affected by the temperature at the time of adult emergence. Protandry may be more evident in males of diapause generations than nondiapause generations because the former emerge in spring 
when the temperature is still low and thus they require a longer time to mature. It is also possible that protandry is more effective in males of diapause generations than nondiapause generations because post-diapause pupae eclose simultaneously; protandry allows male maturity to be attained only at the time of female emergence. Protandry may be less advantageous for non-diapause generations with overlapping generations because of the large variation in the timing of emergence among individuals, and the need for a trade-off between rapid maturation and greater body size (reflecting reproductive capacity). It is controversial whether protandry can be explained as a by-product of sexual size dimorphism (the incidental explanation) or a selection on males to mature before females (the adaptive explanation) (Teder, 2014). The adaptive explanation of protandry argues that the degree of protandry should be insensitive to environmental conditions (Nylin et al., 1993) and that protandry will persist regardless of the developmental pathway (Nylin et al., 1993; Fischer \& Fielder, 2001). However, these arguments may not hold when the insects have overlapping generations, as in P. xuthus.

We propose that the seasonal polyphenism in adult body size in $P$. xuthus is affected by temperature conditions during the larval stage. However, our results do not preclude other adaptive hypotheses for the smaller adult body size of spring generations than summer generations. For example, a smaller body size may be advantageous in terms of thermoregulation in spring. Further studies are needed to reveal the adaptive significance of seasonal polyphenism in adult body size in $P$. xuthus.

ACKNOWLEDGEMENTS. We thank $\mathrm{H}$. Naka for help with making the artificial diet fed to P. xuthus and H. Numata for helpful comments on our experiments. This work was partially supported by JSPS KAKENHI (no. 15K14603).

\section{REFERENCES}

Aalberg Haugen I.M., Berger D. \& Gotthard K. 2012: The evolution of alternative developmental pathways: footprints of selection on life-history traits in a butterfly. $-J$. Evol. Biol. 25: $1377-1388$.

AtKInson D. 1994: Temperature and organism size: a biological law for ectotherms? - Adv. Ecol. Res. 3: 1-58.

ATKINSON D. 1995: Effects of temperature on the size of aquatic ectotherms: exceptions to the genetal rule. $-J$. Therm. Biol. 20: $61-74$.

ATKINSON D. 1996: Ectotherm life-history responses to developmental temperature. In Johnston I.A. \& Bennett A.F. (eds) Animal and Temperature: Phenotypic and Evolutionary Adaptation. Cambridge University Press, Cambridge, UK, pp. 183-292.

BARTOŃ K. 2016: MuMIn: Multi-Model Inference. R Package Ver. 1.15.6. URL: https://CRAN.R-project.org/package=MuMIn.

Bates D., Maechler M., Bolker B. \& Walker S. 2015: Fitting linear mixed-effects models using lme4. - J. Stat. Soft. 67: $1-48$.

Brakefield P.M. \& Frankino W.A. 2009: Polyphenism in Lepidoptera: multidisciplinary approaches to studies of evolution and development. In Ananthakrishnan T.N. \& Whitman D.W. (eds): Phenotypic Plasticity of Insects: Mechanisms \& Consequences. Oxford University Press, Oxford, UK, pp. 337-368.
Cabanita R. \& AtKinson D. 2006: Seasonal time constraints do not explain exceptions to the temperature size rule in ectotherms. - Oikos 114: 431-440.

Chown S.L. \& Gaston K.J. 1999: Exploring links between physiology and ecology at macro-scales: the role of respiratory metabolism in insects. - Biol. Rev. 74: 87-120.

Davidowitz G. \& Nishout H.F. 2004: The physiological basis of reaction norms: The interaction among growth rate, the duration of growth and body size. - Integr. Comp. Biol. 44: 443449.

Fischer K. \& Fiedler K. 2001: Sexual differences in life-history traits in the butterfly Lycaena tityrus: a comparison between direct and diapause development. - Entomol. Exp. Appl. 100: 325-330.

FRIBERG M. \& KARLSSON B. 2010: Life-history polyphenism in the map butterfly (Araschnia levana): developmental constraints versus season-specific adaptations. - Evol. Ecol. Res. 12: 603-615.

Friberg M., Aalberg Haugen I.M., Dahlerus J., Gotthard K. \& WIKLUND C. 2011: Asymmetric life-history decision-making in butterfly larvae. - Oecologia 165: 301-310.

Friberg M., Dahlerus J. \& Wiklund C. 2012: Strategic larval decision-making in a bivoltine butterfly. - Oecologia 169: 623-635.

Fukuda H., Hama E., Kuzuya T., Takahashi A., Takahashi M., TanaKa B., TanaKa H., WakabaYashi M. \& Watanabe Y. 1982: The Life Histories of Butterflies in Japan. Vol. I. Hoikusha, Osaka, $277 \mathrm{pp}$.

GOTTHARD K. 1998: Life history plasticity in the satyrine butterfly Lasiommata petropolitana: investigating an adaptive reaction norm. - J. Evol. Biol. 11: 21-39.

GotTHARD K. 2008: Adaptive growth decisions in butterflies. BioScience 58: 222-230.

GotTHARD K. \& NYLIN S. 1995: Adaptive plasticity and plasticity as an adaptation: a selective review of plasticity in animal morphology and life history. - Oikos 74: 3-17.

GotTHARD K., NyLin S. \& WikLund C. 1994: Adaptive variation in growth rate-life history costs and consequences in the speckled wood butterfly, Pararge aegeria. — Oecologia 99: 281-289.

ICHINOSE T. 1974: Pupal diapause in some Japanese papilionid butterflies, with special reference to the difference in photoperiodic response between the diapausing pupae of Papilio maakii tutanus Fenton and P. xuthus Linnaeus. - Kontyû 42: 439-450.

Kingsolver J.G., Massie K.R., Ragland G.J. \& Smith M.H. 2007: Rapid population divergence in thermal reaction norms for an invading species: breaking the temperature-size rule. J. Evol. Biol. 20: 892-900.

KIVElä S.M., VÄLIMÄKI P. \& Mä̈nPäÄ M.I. 2012: Genetic and phenotypic variation in juvenile development in relation to temperature and development pathway in a geometrid moth. -J. Evol. Biol. 25: 881-891.

Kivelä S.M., VÄLIMÄKi P. \& Gotthard K. 2013: Seasonality maintains alternative life-history phenotypes. - Evolution 67: 3145-3160.

Kivelä S.M., VÄlimäKi P. \& Gotthard K. 2016: Evolution of alternative insect life histories in stochastic seasonal environments. - Ecol. Evol. 6: 5596-5613.

Larsdotter Mellström H., Friberg M., Borg-Karlson A.K., Murtazina R., Palm M. \& Wiklund C. 2010: Seasonal polyphenism in life history traits: time costs of direct development in a butterfly. - Behav. Ecol. Sociobiol. 64: 1377-1383.

LeIMAR O. 1996: Life history plasticity: influence of photoperiod on growth and development in the common blue butterfly. Oikos 76: 228-234. 
Lively C.M. 1986: Canalization versus developmental conversion in a spatially variable environment. - Am. Nat. 128: 561-572.

Moran N.A. 1992: The evolutionary maintenance of alternative phenotypes. - Am. Nat. 139: 971-989.

Nylin S., Wiklund C. \& Wickman P.-O. 1993: Absence of tradeoffs between sexual size dimorphism and early male emergence in a butterfly. - Ecology 74: 1414-1427.

R Core Team 2015: R: A Language and Environment for Statistical Computing. R Foundation for Statistical Computing, Vienna.

Shapiro A.M. 1976: Seasonal polyphenism. - Evol. Biol. 9: 259-333.

TANAKA K. \& TSUBAKI Y. 1984: Seasonal dimorphism, growth and food consumption in the swallowtail butterfly Papilio xuthus L. - Kontyû 52: 390-398.

TAYlor F. \& Spalding J.B. 1989: Timing of diapause in relation to temporally variable catastrophes. - J. Evol. Biol. 2: 285-297.

TeDER T. 2014: Sexual size dimorphism requires a corresponding sex difference in development time: a meta-analysis in insects. - Funct. Ecol. 28: 479-486.

Teder T., Esperk T., Remmel T., Sang A. \& Tammaru T. 2010 Counterintuitive size patterns in bivoltine moths: late-season larvae grow larger despite lower food quality. - Oecologia 162: $117-125$.
VÄlimäKi P., Kivelä S.M., MÄEnpäÄ M.I. \& Tammaru T. 2013a: Latitudinal clines in alternative life histories in a geometrid moth. - J. Evol. Biol. 26: 118-129.

VÄLIMÄKi P., KiVElä S.M. \& MäENPÄÄ M.I. 2013b: Temperature- and density-dependence of diapause induction and its life history correlates in the geometrid moth Chiasmia clathrata (Lepidoptera: Geometridae). - Evol. Ecol. 27: 1217-1233.

Välimäki P., Kivelä S.M., Raitanen J., Pakanen V.M., Vatka E., MäenpäÄ M.I., Keret N. \& Tammaru T. 2015: Larval melanism in a geometrid moth: promoted neither by a thermal nor seasonal adaptation but desiccating environments. - J. Anim. Ecol. 84: 817-828.

Watanabe M. \& Nozato K. 1986: Fecundity of the yellow swallowtail butterflies, Papilio xuhus and P. machaon Hippocrates, in a wild environment. - Zool. Sci. 3: 509-516.

WiKLUND C. \& FrIBERG M. 2011: Seasonal development and variation in abundance among four annual flight periods in a butterfly: a 20-year study of the speckled wood (Pararge aegeria). - Biol. J. Linn. Soc. 102: 635-649.

WikLund C., Nylin S. \& Forsberg J. 1991: Sex-related variation in growth-rate as a result of selection for large size and protandry in a bivoltine butterfly, Pieris napi. - Oikos 60: 241-250.

Received July 27, 2016; revised and accepted July 31, 2017 Published online August 14, 2017 